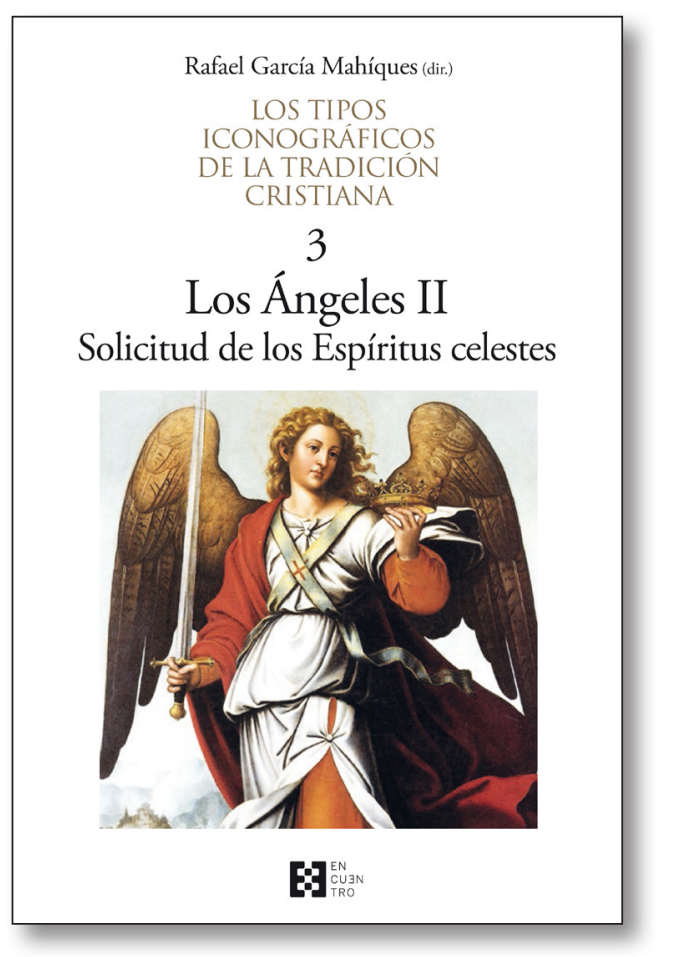

\section{Los tipos iconográficos de la tradición cristiana, vol. 3. Los Ángeles II. Solicitud de los Espíritus celestes \\ Rafael García Mahíques (dir.)}

Ediciones Encuentro, Madrid, 2017, 588 pp.

Estamos ante el tercer volumen de la colección Los Tipos ICONOGRÁficos DE LA TRAdición CRISTIANA, y el segundo sobre los Ángeles. Por lo tanto puede decirse que esta colección, con la edición de un volumen anual, se va consolidando. Nuevamente ahora, como en anteriores recensiones, se impone subrayar la importancia de este enfoque en el vasto campo de la iconografía, el cual consiste en compilar de un modo sistemático los tipos iconográficos de la cultura cristiana conformando un tratado que pueda reunir toda la tradición visual elaborada por la cristiandad a través de los siglos. Se justifica por el hecho de que lo elaborado hasta hoy en dicho sentido (L. Réau, Schiller, etc.), aunque muy importante, queda ya obsoleto y sobre todo ha obviado la manifestación hispánica de dicha tradición, aspecto esencial del presente proyecto que pretende justamente ofrecer una visión universal pero recuperando en su justo valor la producción iberoamericana. Se justifica así mismo también por la necesidad de que la disciplina histórico-artística en la universidad española tenga unos referentes dignos que puedan afianzar con calidad los estudios sobre iconografía y cultura visual. Esta propuesta, por lo tanto, aspira a afianzarse con vocación de perdurabilidad.

Perfiles básicos de este proyecto son determinados conceptos que han requerido una definición terminológica, esperando reunir un amplio consenso dentro de la comunidad científica de la Historia del arte del ámbito hispánico, máxime cuando esta comunidad no ha logrado aún establecer con claridad esta clase de definiciones, algo explicable en su mayor parte por la secular hegemonía que ha impuesto el formalismo dentro de esta tradición de estudios. Así, un término central que cada vez va siendo más utilizado por los historiadores -aunque en ocasiones de un modo arbitrario-, es el de «tipo iconográfico», el cual ocupa aquí una posición medular. En realidad se trata de un concepto muy propio de la universal 
tradición de estudios iconográficos que no había logrado una apropiada implantación por razones de mentalidad metodológica. Este término normalmente venía siendo substituido por otros más acordes con la valoración formal del hecho artístico: "modelo», "patrón», «figuración», o bien "iconografía» no en su sentido propio, sino inadecuadamente como «contenido de la representación». El término es de tradición panoskiana y se encuentra perfectamente perfilado universalmente en el conjunto de los estudios iconográficos de todo el mundo. Fue introducido por el mismo Panofsky en 1932 -aún en su etapa alemana-, en aquel importante ensayo en la revista Logos, y empleado sucesivamente en toda su obra posterior tanto en alemán como en inglés. R. García Mahíques la ha llegado a definir como el modo como un tema -un concepto extra-artístico propio de la cultura- se convierte en imagen a partir de la voluntad de ser representado visualmente. Por lo tanto, «tipo iconográfico» es el concepto propio y exacto que debe corregir expresiones tan impropias como: "modelo iconográfico», "representación iconográfica», o "una iconografía», solo por citar tres casos bastante frecuentes. Otros conceptos de índole semejante que dentro de este proyecto tienen una vigencia central son los de "conceptual" y "narrativo" -calificativos definitorios aplicables tanto a "tipo iconográfico» como sencillamente a «imagen»-, cuya esencia no es otra que la distinción entre una imagen atemporal o bien precisada como momento de una narración.

Se trata aquí de un segundo volumen sobre los ángeles que completa la entrega anterior tratando de fijar los aspectos esenciales que la tradición visual cristiana ha ido codificando. Tras una introducción de carácter teórico o especulativo sobre la mediación angélica, que sirve de enlace con el anterior volumen, comienza con un capítulo fundamental dedicado a los Siete Príncipes angélicos y los ángeles apócrifos, algo que en la tradición de estudios se suelen casi siempre confundir bajo el común enunciado de "apócrifos». Se esclarece aquí de un modo muy concluyente que los Siete Príncipes o Arcángeles, tienen un perfil concreto, implantado en la tradición cristiana desde el siglo XVI, y que en cierta manera su enraizamiento tiene relación con la decadencia de la estructuración angélica en jerarquías -gregoriana y dionisiana-, la cual prácticamente quedará olvidada en la visualidad cristiana de la Edad Moderna. Los ángeles apócrifos, en cambio serán aquellos que han sido identificados con un nombre y un atributo a partir de determinadas fuentes literarias, y que habrían recibido culto en algún lugar, aparte de los considerados como canónicos: Rafael, Gabriel y Miguel.

A continuación, sigue el capítulo dedicado a la actividad angélica, que conforma el grueso principal de este volumen y que tiene la virtud de presentarnos toda la actividad terrena de los ángeles en el contexto de la Historia de la Salvación, lo que irá agrupado en diferentes apartados. De este modo cobra así sentido una oportuna agrupación temática de la actividad de los ángeles: en torno a los episodios de las Escrituras, en el Antiguo Testamento y en torno a Cristo en el Nuevo Testamento; en torno a la Virgen María; en torno a los santos; como ángeles adorantes, ceroferarios y turiferarios; los ángeles combatientes; los ángeles custodios, en sus diferentes modalidades como ángeles custodios de ciudades, instituciones, y como Ángel de la guarda; y por último la actividad en torno a las postrimerías y el Juicio Final. Ha sido el resultado de un deliberado esfuerzo de sistematización no logrado hasta el momento, aunque siempre quedará el Iconclass, que en el fondo ha sido también un referente fundamental en el conjunto del proyecto.

El tema de los ángeles tendrá en 2018 un tercer volumen: «la música del Cielo» dedicado a su actividad musical, un capítulo aún no abordado por los estudios iconográficos y que tendrá la particularidad de ser absolutamente novedoso. Por último, cabe aquí también re- 
cordar que todo este proyecto está siendo llevado a cabo por el grupo de investigación APES, radicado en la Universitat de València, pero conformado por un conjunto de especialistas en iconografía cristiana de diferentes universidades, a cuyo frente se encuentra Rafael García Mahíques, catedrático de Historia del arte, quien lleva a cabo la triple función de director, elaborando el diseño del plan a seguir, coordinador de las tareas de los diferentes investigadores y editor de los textos.

$M^{a}$ Elvira Mocholí Martínez Universitat de València 
